\author{
Why you should read this article: \\ - To familiarise yourself with the concept of masculinity ideology \\ - To improve your knowledge of the influence that masculinity ideology has on a person's self-care behaviours \\ - To understand how Orem's self-care theory can provide a conceptual framework for men's health
}

\title{
Use of Orem's self-care model to understand how traditional masculinity affects men's health
}

\author{
Wilfred Michael Allen
}

\begin{abstract}
Citation
Allen WM (2021) Use of

Orem's self-care model to understand how traditional masculinity affects men's health. Primary Health Care. doi: 10.7748/phc.2021.e1691
\end{abstract}

\section{Peer review \\ This article has been subject to external double-blind peer review and has been checked for plagiarism using automated software}

Correspondence allenwm@udmercy.edu

\section{Conflict of interest}

None declared

Accepted

7 September 2020

Published online

February 2021

\section{Gopen access}

This is an open access article distributed under the terms of the Creative Commons Attribution 4.0 International licence (CC BY 4.0) (see https:// creativecommons.org/licenses/ by/4.0/), which permits others to copy and redistribute in any medium or format, remix, transform and build on this work, even commercially, provided appropriate credit is given and any changes made indicated

\begin{abstract}
Masculinity ideology, particularly traditional masculinity ideology, has been identified as an influential factor in the healthcare decisions taken by men. Orem's theory of self-care can be applied to explain the influence that masculinity ideology has on a person's self-care behaviours. Use of Orem's theory can give nurses a conceptual frame of reference by which they can examine masculinity ideology in its relation to self-care behaviours among men of various races and cultural backgrounds.
\end{abstract}

\section{Author details \\ Wilfred Michael Allen, assistant professor, University of Detroit Mercy, Detroit, Michigan, US}

Keywords

behaviour change, culture, diversity, health promotion, lifestyles, transcultural care, self-care, men's health

\section{Introduction}

Of the various factors that influence health outcomes, self-care practices, specifically health behaviours, have a significant role in morbidity and mortality. Since self-care is identified as having an important role in the management and outcomes of chronic illnesses (Qoli et al 2016), and engaging in factors that promote a healthy lifestyle may decrease the rates of mortality (Loef and Walach 2012), there is a need to explore potential underlying factors that may affect a person's engagement in self-care.

Non-adherence to treatment regimens can be an issue, particularly outside acute care, where there is a greater need for patient responsibility and self-care (Jallinoja et al 2007). Failure to appropriately seek professional assistance and follow treatment plans, and deficiencies in the way individuals care for their own health can affect the course and outcomes of acute and chronic illness (Sanders Thompson et al
2009). These risky health behaviours have also been associated with men who endorse a traditional masculine ideology (Mahalik et al 2007). Orem's (2001) theory of self-care provides an explanatory framework for examining self-care practices and the influence that masculinity ideology plays on self-care behaviours among men.

\section{Masculinity ideology}

Masculinity ideology is defined as the internalised systems of beliefs and attitudes that generate and coordinate an individual's expectations, goals and behaviours in congruence with the culturally defined standards of the male role (Pleck et al 1993, Levant and Richmond 2007). Although this is a recognised definition of masculinity ideology, it is not an all-encompassing universal standard. Masculinity ideology reflects an individual's culture (Levant et al 2003), producing the construction of diverse masculinity ideologies (Pleck 1995). 
Masculinity ideologies are comprised of socially acceptable ways for boys and men to think, feel and behave (Mahalik et al 2003). A person's perception of social norms, such as masculinity ideology, influences their health behaviours (Mahalik et al 2007).

There is no evidence of a predetermined biological essence that contributes to the development of masculinity ideology. Differences in socioeconomic status, education, age and race are among the factors that influence the development of masculinity ideology (Kimmel and Messner 1992). Although masculinity ideology may be diverse across various cultures, there are certain standards and expectations that are commonly associated with the traditional male role. Those that adhere to these common standards and expectations have been referred to as having a traditional masculinity ideology (Pleck 1995).

\section{Traditional masculinity ideology}

Traditional masculinity ideology is a cultural dynamic with a long-established history of defining 'what it means to be a man'. Men of certain cultures are inhibited when it comes to exhibiting behaviours or thoughts attributed to the female role. Those who endorse traditional masculinity ideology adhere to a wide range of specific behaviours and self-perceptions that comprise a cultural expectation for men (Wade 2008). For example, one of the central norms of traditional masculinity ideology is restrictive emotionality; thus, being viewed crying in public would be a violation of this norm for men who endorse traditional masculinity ideology (Eisler and Skidmore 1987). Achievement, self-reliance, a reluctance to consult medical and mental health care providers (Addis and Mahalik 2003), and suboptimal use of preventive healthcare (Mahalik et al 2006) have been associated with traditional masculinity ideology. Research has suggested that men who endorse a traditional masculinity ideology are also more likely to engage in risky health behaviours (Mahalik et al 2007).

Since health behaviours such as selfcare have been identified as an important component in the prevention and management of chronic illness (Becker et al 2004), consideration must be given to the potential influence that masculinity ideology has on health behaviours. With the potential influence that masculinity ideology has on self-care practices - in relation to health behaviours and ultimately health outcomes - it is essential to examine which aspects of masculinity ideology are most influential.

\section{Orem's theory of self-care and traditional masculinity}

An examination of the theory of self-care (Orem 2001) reveals various concepts including basic conditioning factors (BCFs) and self-care agency with its tier of constructs. The theory of selfcare provides a description and explanation of why and how individuals care for themselves.

Although Orem's theory of self-care included the concept of therapeutic self-care demand, the theory of self-care - with its explanation of how specific human factors may influence self-care - is the focus. Figure 1 shows a proposed theoretical model of self-care at the conceptual and theoretical levels, as adapted from Orem's (2001) self-care deficit theory.

The conceptual level represents the relationship of BCFs such as age and gender to self-care agency, and how this relationship influences self-care and ultimately health. The theoretical level depicts the relationship between specific BCFs and constructs of self-care agency, and how this relationship influences self-care and eventually health outcomes.

Figure I. Proposed theoretical model at conceptual and theoretical levels

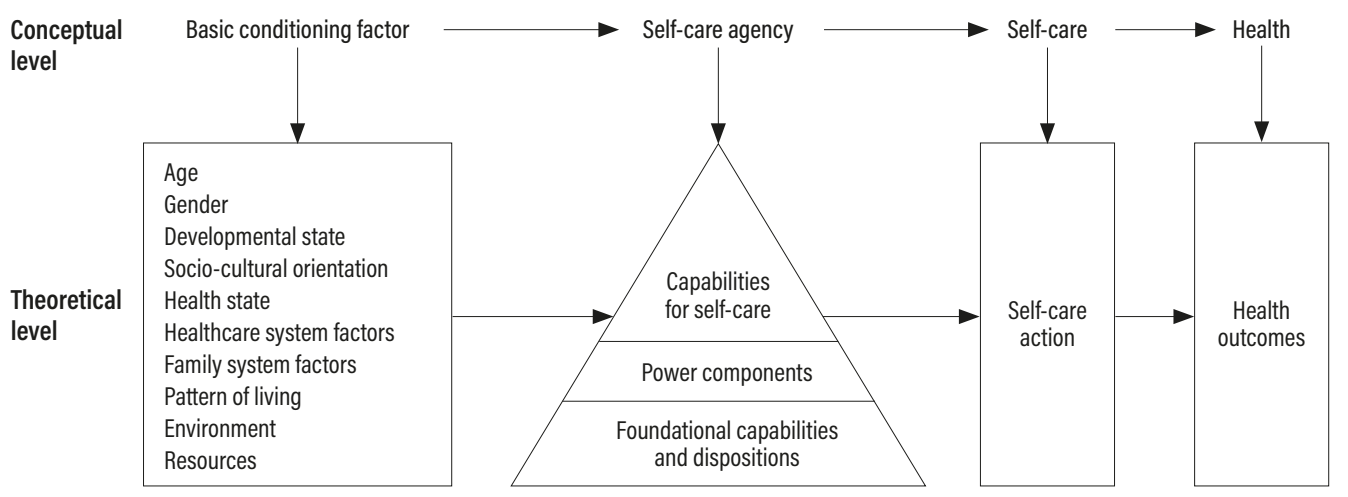




\author{
Basic conditioning factors \\ $\mathrm{BCF}$ are defined as 'personal conditions \\ or environmental circumstances' that \\ may influence individual competence for \\ engagement in self-care actions (Orem 2001). \\ There are ten BCFs (Orem 2001): \\ " Age. \\ ॥ Gender. \\ ॥ Developmental state. \\ » Health state. \\ 》 Socio-cultural orientation. \\ » Healthcare system. \\ ॥ Family system factors. \\ ॥ Pattern of living. \\ » Environmental factors. \\ » Resource availability and adequacy. \\ BCFs involve cultural, environmental, \\ socioeconomic conditions and other human \\ conditions. They affect a person's self- \\ care agency, that is the 'complex acquired \\ capability to meet one's continuing \\ requirements for care of self that regulates life \\ processes, maintains or promotes integrity of \\ human structure and functioning and human \\ development, and promotes well-being' \\ (Orem 2001). Racial identity is an addition to \\ the conceptualised BCFs with a focus on its \\ relationship with masculinity ideology.
}

Racial identity as a basic conditioning factor Racial identity is developed through cultural socialisation, personal experiences and lifelong learning, and may have an influence on the development of how masculinity ideology affects a person's self-care agency. The influence of racial identity may be an underlying phenomenon resulting from the way in which it is conceptualised during socialisation. The conceptualisation of racial identity is considered a BCF because the sociocultural orientation may affect an individual's engagement in self-care. Although Orem (2001) named ten BCFs, she acknowledged that they 'should be amended whenever a new factor is identified'.

Since the development and operability of self-care agency can be influenced by BCFs, it is essential that these factors are understood when assessing an individual's ability to undertake self-care activities. An in-depth knowledge of these factors is required for a more complete understanding of the influences they may exert on self-care agency.

\section{Permission}

To reuse this article or for information about reprints and permissions, please contact permissions@rcni.com

\section{Self-care agency}

Like masculinity ideology, self-care agency is derived from cultural socialisation, personal experiences, and knowledge acquired throughout a maturing individual's lifespan.
Self-care agency is a multidimensional concept consisting of an organised hierarchy of three: a basis of foundational capabilities and dispositions; power components as an enabler for self-care operations; and capabilities for self-care operations (Orem 2001).

\section{Foundational capabilities and dispositions}

The foundational capabilities and dispositions form the base of the hierarchy of constructs that comprise self-care agency. Foundational capabilities are the sensations, perceptions and physical movements that are essential for individuals engaging in self-care.

Foundational dispositions refer to the common, prevailing attitudes a person holds, and which affect the goals they seek. These dispositions affect a person's willingness to view themselves as self-care agents and include constructs such as self-understanding, self-awareness, selfconcept, self-image, self-value, self-acceptance, self-concern, and willingness to meet self-needs. These dispositions affect the power component of motivation. For example, an individual's perception of their worth as a person (selfvalue) can affect the self-care operations required to engage in self-care behaviour (Orem 2001).

\section{Power components}

The power components comprise the middle layer of the self-care agency hierarchy of constructs. Power and capabilities are synonymous in their meaning. The power that an individual possesses means that a certain activity can be undertaken, not necessarily that it will be undertaken (Orem 2001). There are ten power components of selfcare agency necessary to undertake self-care. These comprise the ability to (Orem 2001):

» Maintain attention and exercise vigilance with regards to self as self-care agent.

॥ Control the use of physical energy.

» Execute and control body movements for self-care.

॥ Be rational within a self-care frame of reference.

» Make decisions regarding self-care and operationalise those decisions.

» Access motivation for self-care.

" Acquire, retain and operationalise knowledge related to self-care.

» Acquire a range of skills to undertake self-care operations.

॥ Prioritise discrete self-care actions with previous and subsequent actions towards the goals of self-care.

॥ Undertake self-care operations and integrate them with other aspects of living on a consistent basis. 


\section{Capabilities for self-care operations} The top layer of self-care agency's hierarchal structure consists of three self-care operations delineated by Orem (2001): estimative operation, transitional operations and productive operations. The estimative operation phase involves examining what actions need to be taken and becoming knowledgeable about one's self, the meaning of the existent conditions and the means available for effective regulation of self-care. The transitional operation phase includes judgements regarding the preferred course of self-care and decisions about whether or not to engage in regulatory self-care operations. The productive operation phase is when goals are set and plans of action specified.

\section{Relationship between masculinity ideology and self-care agency}

It is worth considering the comparison between the recognised constructs of masculinity ideology (such as self-image, self-value and self-awareness) as identified by other researchers (Majors and Billson 1992, Addis and Mahalik 2003, Roberts-Douglass and Curtis-Boles 2013), and the dispositions that can affect an individual's goal-seeking (such as self-confidence, self-reliance and self-esteem), as identified by Orem (2001).

Table 1 shows a comparison of Orem's (2001) foundational dispositions and the constructs of masculinity ideology. Based on

\begin{tabular}{l|l|}
$\begin{array}{l}\text { Table I. Comparison of Orem's (2001) } \\
\text { foundational dispositions and the } \\
\text { constructs of masculinity ideology }\end{array}$ \\
\hline $\begin{array}{l}\text { Constructs of the dispositions } \\
\text { affecting goals sought }\end{array}$ & $\begin{array}{l}\text { Constructs of } \\
\text { masculinity ideology }\end{array}$ \\
\hline Self-image & Self-image \\
\hline Self-value & Self-confidence \\
\hline Self-awareness & Self-reliance \\
\hline Self-concept & Self-esteem \\
\hline Self-acceptance & Self-awareness \\
\hline Self-concern & Values \\
\hline Self-understanding & Willingness to seek \\
\hline Willingness to meet needs & assistance \\
\hline of self & \\
\hline
\end{tabular}

the similarities, masculinity ideology aligns with dispositions affecting goals sought.

Masculinity ideology conceptualised as a foundational disposition reflects the gender-based beliefs and values that affect a person's willingness to meet self-care needs or to seek appropriate support in meeting those needs. Studies involving the use of healthcare services, specifically among African-American men, suggest that the men's decisions regarding self-care are associated with their formulation of masculinity ideology (Whitley et al 2005, Wade 2008, Hammond et al 2010).

As a foundational disposition, the beliefs and attitudes that generate a person's expectations, goals and behaviours - in congruence with their culturally defined standards of the male role (Pleck et al 1993, Levant and Richmond 2007) - will affect their willingness to view themselves as a self-care agent and accept being in need of, or having the ability to undertake, self-care measures.

\section{Culture as a basic conditioning factor in men}

Based on Brannon's (1976) analysis of what a man is 'supposed to be' in US culture, Brannon and Juni (1984) developed the Brannon Masculinity Scale. This 110-item scale measures an individual's approval of the norms and values that define the male role. For the purposes of this scale, masculinity ideology was conceptualised using four norms, which were defined by David and Brannon (1976):

» 'No sissy stuff' - men should not engage in feminine behaviours.

" 'The big wheel' - achievement and success should be a man's focus.

॥' 'The sturdy oak' - men should not show indications of weakness.

» 'Give 'em hell' - men should search for adventure despite any risks of violence.

Men have traditionally been raised to be strong and silent, and act as providers for their families while avoiding vulnerability, tender emotions and femininity. These characteristics were assimilated into a set of seven traditional male role norms ascribed by Levant et al (1992): avoiding femininity, restrictive emotionality, seeking achievement and status, self-reliance, aggression, homophobia and non-relational attitudes toward sexuality.

The degree to which these characteristics are instilled in a man is determined primarily by the culture in which he is raised. Although culture has many proposed definitions, it is 
defined here as acquired patterns of behaviour, beliefs, lifestyles and characteristic thoughts that contribute to the world-views and decision-making of a certain population of people (Purnell and Paulanka 2008).

During their development, men learn to evaluate their adequacy by matching their preferences, beliefs, attitudes, behaviours and personal attributes with the norms of the culture to which they belong. In their formative years, men begin to internalise motivational factors that prompt them to regulate their behaviour so that it conforms to the culture's definition of masculinity (Bem 1981). The formulation of these internalised factors is what constitutes a person's masculinity ideology, and the health behaviour of male participants has been found to be significantly predicted by the perceived normative behaviour of other men in the same culture (Mahalik et al 2007).

Race and culture have accounted for many of the differences in the ways that men subscribe to being masculine (Brod 1987, Kimmel and Messner 1992). Assumptions have been made that the socialisation of men is congruent with the standards of masculinity for their culture (Carter et al 2005). However, there are factors that influence the socialisation of men from differing racial and ethnic groups. Socio-political histories, in combination with the relationships these groups have with the dominant race and culture, causes variations in the development of racial identity (Carter 1995, Helms 1996, Sue and Sue 2013). These variations could influence the unique way men with differing racial identities understand and express masculinity (Carter 1995).

\section{Incorporating racial identity as a basic conditioning factor} Studies (Denyes et al 2001, Sousa et al 2005, Callaghan 2006) have used demographic questionnaires to assess BCFs, including race, to identify potentially significant relationships. These studies used a demographic questionnaire to assess race as a BCF, with participants asked to identify their racial origin. Although race is an important component to consider when assessing BCFs, asking participants to identify their racial origin alone may project the assumption that members of a specific racial group homogeneously identify with that group. Given that racial identity is developed through cultural socialisation and personal experiences, it is reasonable to expect differences among members of the same racial group, necessitating the need to explore the dimensions of racial identity as a BCF. Since racial identity has dynamic properties that may influence the development of masculinity ideology and ultimately a person's self-care agency, both components must be considered when addressing health behaviours.

Figure 2 shows the relationship between BCFs, masculinity ideology and health behaviours using Orem's nursing theory of self-care; it enables an exploration of the strengths of relationships between BCFs, the foundational disposition of self-care agency and self-care.

\section{Implications for nurses}

Nurses must diagnose an individual's ability to engage in self-care at the time of the initial assessment as well as in the future. Nurses

Figure 2. Relationship between basic conditioning factors, masculinity ideology and health behaviours

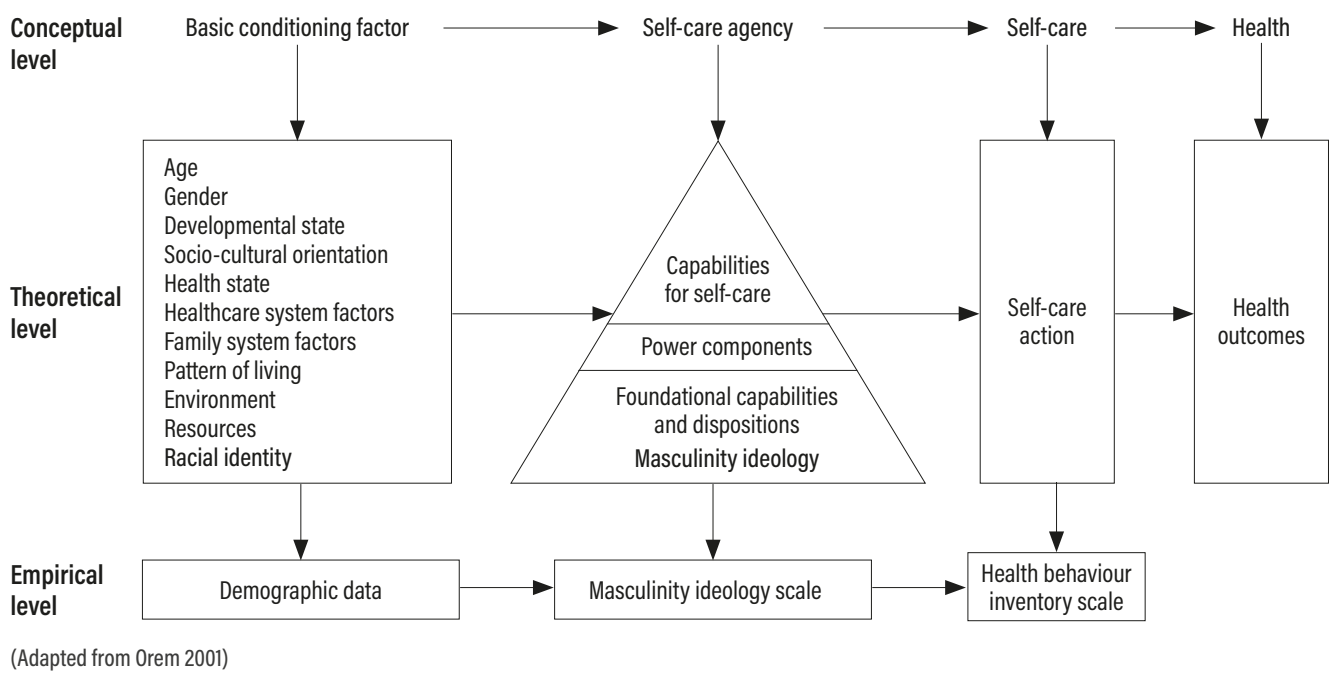


must accurately assess patients' self-care agency to establish their rationale for making judgements. In this way, the nurse can choose a reliable and valid method of providing support, as well as designing and implementing care plans (Orem 2001).

Given that modern healthcare is focused on addressing the causes of preventable morbidity and mortality, and on the promotion of health, the reactive stance of treating diseases could no longer dominate healthcare systems (Koh et al 2014). Consequently, nurses must take an aggressive approach to the promotion of health through research-acquired knowledge.

An understanding of masculinity ideology as it relates to healthcare behaviours has the potential to guide nurses in formulating comprehensive assessment tools and care plans. Orem's (2001) self-care theory allows nurses a conceptual frame of reference by which they can examine masculinity ideology in its relation to self-care behaviours among men of various races.

\section{Conclusion}

It is imperative that healthcare providers understand the specific aspects of masculinity ideology that have the potential to affect selfcare behaviours, particularly among men from diverse racial backgrounds.

Self-care is crucial to the promotion of health and the prevention of complications during treatment, recovery and rehabilitation from disease. Masculinity ideology is a critical dispositional variable among men from different cultures that deserves ongoing examination to understand its influence on self-care behaviours.

\section{References}

Addis ME, Mahalik JR (2003) Men

masculinity, and the contexts of help-

seeking. American Psychologist. 58, 1, 5-14

doi: 10.1037/0003-066x.58.1.5

Becker G, Gates RJ, Newsom E (2004) Self-care among chronically ill African Americans: culture health disparities, and health insurance status. American Journal of Public Health. 94, 12, 2066-2073. doi: 10.2105/AJPH.94.12.2066

Bem SL (1981) Gender schema theory: a cognitive account of sex typing. Psychology Review. 88, 4, 354-364. doi: 10.1037/0033-295X.88.4.354

Brannon R (1976) The male sex role: our culture's blueprint for manhood, what it's done for us lately. In David D, Brannon R (Eds) The Forty-Nine Percent Majority: The Male Sex Role. Addison-Wesley,

Reading MA, 1-49.

Brannon R, Juni S (1984) A scale for measuring attitudes about masculinity. Psychological Documents. 14, 6-7.

Brod H (1987) The Making of the Masculinities: The New Men's Studies. Unwin Hyman, Boston MA.

Callaghan D (2006) Basic conditioning factors' influences on adolescents' healthy behaviors, self-efficacy, and self-care. Issues in Comprehensive Pediatric Nursing. 29, 4, 191-204 doi: 10.1080/01460860601087156

Carter RT (1995) The Influence of Race and Racial Identity in Psychotherapy: Toward a Racia Inclusive Model. Wiley, New York NY

Carter RT, Williams B, Juby HL et al (2005) Racial identity as mediator of the relationship between gender role conflict and severity of psychological symptoms in Black, Latino, and Asian men. Sex Roles. 53, 473-486. doi: 10.1007/s11199-005-7135-7

David D, Brannon R (Eds) (1976) The Forty-Nine Percent Majority: The Male Sex Role. AddisonWesley, Reading MA.
Denyes MJ, Orem DE, Bekel G (2001) Self-care: a foundational science Nursing Science Quarterly. 14, 1, 48-54. doi: 10.1177/089431840101400113

Eisler RM, Skidmore JR (1987) Masculine gender role stress: scale development and component factors in the appraisal of stressful situations. Behavior Modification. 11, 2, 123-136. doi: $10.1177 / 01454455870112001$

Hammond WP, Matthews D, Corbie-Smith G (2010) Psychosocial factors associated with routin health examination scheduling and receipt among African-American men. Journal of the National Medical Association. 102, 4, 276-289. doi: 10.1016/S0027-9684(15)30600-3

Helms JE (1996) Towards an approach for assessing racial identity. In Impara JC, Sodowsky GR (Eds) Multicultural Assessment in Counseling and Clinical Psychology. Buros Institute of Mental Measurements, Lincoln NE, 143-192.

Jallinoja P, Absetz P, Kuronen R et al (2007) The dilemma of patient responsibility for lifestyle change: perceptions among primary care physicians and nurses. Scandinavian Journal of Primary Health Care. 25, 4, 244-249. doi: $101080 / 02813430701691778$

Kimmel MS, Messner MA (1992) Men's Lives. Second edition. Macmillan, New York NY.

Koh HK, Blakey CR, Roper AY (2014) Healthy people 2020: a report card on health of the nation. Journal of the American Medical Association. 311, 24, 2475-2476. doi: 10.1001/jama.2014.6446

Levant RF, Cuthbert AC, Richmond Ket al (2003) Masculinity ideology among Russian and U.S. young men and women and its relationship to unhealthy habits among young Russian men. Psychology of Men and Masculinity. 4,1, 26-36. doi: 10.1037/1524-9220.4.1.26
Levant RF, Hirsch L, Celentano E et al (1992) The male role: an investigation of norms and stereotypes. Journal of Mental Health Counseling 14,3,325-337.

Levant RF, Richmond K (2007) A review of research on masculinity ideologies using the male role norms inventory. Journal of Men's Studies. 15, 2, 130-146. doi: 10.3149/jms.1502.130

Loef M, Walach H (2012) The combined effects of healthy lifestyle behaviors on all cause mortality: a systematic review and metaanalysis. Preventive Medicine. 55, 3, 163-170. doi: 10.1016/j.ypmed.2012.06.017

Mahalik JR, Burns SM, Syzdek M (2007) Masculinity and perceived normative health behaviors as predictors of men's health behaviors. Social Science and Medicine. 64, 11, 2201-2209. doi: 10.1016/.jsocscimed.2007.02.035

Mahalik JR, Lagan HD, Morrison JA (2006) Health behaviors and masculinity in Kenyan and U.S. male college students. Psychology of Men and Masculinity. 7, 4, 191-202. doi: 10.1037/1524-9220.7.4.191

Mahalik JR, Locke BD, Ludlow LH et al (2003) Development of the conformity to masculinity norms inventory. Psychology of Men and Masculinity. 4, 1, 3-25. doi: 10.1037/1524-9220.4.1.3

Majors R, Billson JM (1992) Cool Pose: The Dilemmas of Black Manhood in America. Simon and Schuster New York NY.

Orem D (2001) Nursing: Concepts of Practice. Sixth edition. Mosby, St. Louis MO

Pleck JH, Sonenstein FL, Ku LC (1993) Masculinity ideology and its correlates. In Oskamp S, Costanzo M (Eds) Gender Issues in Social Psychology. Sage, Newbury Park CA, 85-110.
Pleck JH (1995) The gender role strain paradigm: an update. In Levant RE PollackWS (Eds) A New Psychology of Men. Basic Books, New York NY, 11-32.

Purnell LD, Paulanka BJ (2008) Transcultural Health Care: A Culturally Competent Approach. Third edition. F. A. Davis Company, Philadelphia PA.

Qoli A, Nasrabadi T, Abianeh EE (2016) The effect of educational self-care program on knowledge and performance in patients with coronary syndrome. International Journal of Medical Research \& Health Sciences. 5, 5(S), 132-137.

Roberts-Douglass K, Curtis-Boles H (2013) Exploring positive masculinity development in African American men: a retrospective study. Psychology of Men \& Masculinity. 14, 1, 7-15. doi: 10.1037/a0029662

Sanders Thompson VL, Talley M, Caito $\mathrm{N}$ et al (2009) African American men's perceptions of factors influencing health-information seeking. American Journal of Men's Health. 3, 1, 6-15. doi: 10.1177/1557988307304630

Sousa VD, Zauszniewski JA, Musil CM et al (2005) Relationships among self-care agency, selfefficacy, self-care, and glycemic control. Research and Theory for Nursing Practice. 19, 3, 217-230 doi: 10.1891/rtnp.2005.19.3.217

Sue DW, Sue D (2013) Counseling the Culturally Diverse: Theory and Practice. Sixth edition. Wiley \& Sons, Hoboken, NJ.

Wade JC (2008) Masculinity ideology, male reference group identity dependence, and African American men's health-related attitudes and behaviors. Psychology of Men \& Masculinity. 9,1,5-16. doi: 10.1037/1524-9220.9.1.5

Whitley EM, Samuels BA, Wright RA et a (2005) Identification of barriers to healthcare access for underserved men in Denver. Journa of Men's Health and Gender. 2, 4, 421-428. doi: 10.1016/j.jmhg.2005.05.006 